IJTAR

International Journal of Transactional Analysis Research
5 (2), 3-16

https://doi.org/10.29044/v5i2p3

\title{
Systemic Transactional Analysis Coaching: A study of effective conditions, consequences and effects on organisational culture
}

\author{
(C) 2014 Günther Mohr
}

\begin{abstract}
The paper describes content and process of an ongoing in-house 'individual coached within a group' coaching programme run over many years in Germany, utilising various concepts including classical, systemic and systemic organisational transactional analysis and three sequential research studies covering the perceived usefulness of the coaching programme to individuals and their organisation, the correlations between attendance at the programme and professional advancement within the organisation, and the factors identified by participants as contributing to the effectiveness of the programme

The initial survey-based study identified the primary factor as the extent to which participants had been able to deal with their personally-identified most important individual issue or problem. The second study applied QCA (Qualitative Comparative Analysis) (Ragin 1987, 2000, 2008) and showed a correlation between the autonomous variables of participation in the group and the interdependent variable of 'additional empowerment' by the company. The third study used frequency and valence analysis of responses to a questionnaire completed by 38 managers to identify the key elements that they believed contributed to the effectiveness of the coaching programme.
\end{abstract}

The author concludes that such programmes are effective but complex so require the coach to have psychological, pedagogical, leadership and management expertise and that this be applied within an organisational learning culture.

\section{Key words}

effectiveness research, in-house coaching, group coaching, , transactional analysis, systemic transactional analysis, qualitative comparative analysis, valence analysis, frequency analysis

\section{Introduction}

Today there are numerous different approaches and models of coaching, which this author describes as a professional relationship in which a coach works with a client to achieve certain goals of the client in terms of personal and professional competencies. The current series of three linked studies concerns coaching in the group, which the Deutscher Bundesverband Coaching (2012) (DBVC, German Coaching Association) describes as "a coaching type with several persons without interdependencies being coached as a group. Their issues are thematically oriented in a way that makes sure the participants are able to learn from each other and with each other" (p. 30). The coaching system presented in this project falls within this category with one exception, in that the main focus was not coaching the group but coaching the individual in the group. Systemic transactional analysis, as a combination of transactional analysis and systemic concepts, both coming from short term counselling approaches, are the source of the methods used in the coaching.

\section{Literature Review - Coaching research in general and for the group coaching setting}

Coaching research is not far developed in the provision of evidence that really describes the field in its core, results and impacts. As an anonymous coach said - "We need evidence-based coaching more than eminencebased coaching".

Carter (2013) suggests that coaching programmes are sets of organised coaching relationships. Commenting on her research in British companies and public institutions that coaching is often combined with training, she points out that scientific evaluation has not become part of the standard and recommends study of the success factors of coaching programs, under which she 
subsumes the company context, the program design and the stakeholders.

After looking at the state of the art in coaching research, Cushion \& Lyle (2013) concludes that "Coaching research is not yet at a stage where the influence of funding agencies or publishing policies impacts the 'weight of focused research'. A diverse research community or 'schools' have developed reflecting personal agendas that are seldom coaching specific, but driven by disciplinary or sub-disciplinary outcomes. This may be understandable in an under-theorised field, but recourse to models and theories from other fields has limited value in building a coherent conceptual or theoretical body of knowledge . . . Too often, this means that the 'coaching' within the research is superficial or secondary." (p. 104)

"A critical examination of the field in terms of conceptual development, research direction and research evidence provides a framework to understand and bridge the 'theory-practice' gap (p. 101). Coaching remains, relatively speaking, under-researched with existing research tending to be "sparse, unfocussed and subjective" (LeUnes, 2007, p. 403, quoted by Cushion \& Lyle, 2013, p. 103).

Other researchers have a more optimistic view. Although coaching is relatively new, its research may be biased by commercial interests, it is close to other professional applications and there are a lot of research results that we can use like pieces in a puzzle. According to Möller and Kotte (2012) research on the effectiveness, preconditions and factors for effectiveness is in a beginning state. In their eyes the kind of research papers available offer the same variety as the very diverse market (Ely et al. 2010, Greif 2008; Künzli 2009).

Greif (2008) of the University of Osnabrück looked over the whole research literature on coaching and developed a structure model for the effects of result oriented coaching:

1. Preconditions - on the side of the coach and the client

2. Success factors

3. Specific results

4. General applicable results.

Kirkpatrick (2006) proposed a four-level-taxonomy for evaluation

1. 'Happiness'-Indices - Surveys on consumer satisfaction

2. Measurement of Learning - changed skills, changed attitudes

3. Measurement of Transfers - behaviour changes at the work place

4. Evaluation of the economic success - return on investment

For the field of coaching in the group we can build on the results that Ebner (2013) posits to be the advantages and disadvantages of coaching in the group, as in Table 1.

\begin{tabular}{|c|c|}
\hline Advantages of the group context & Disadvantages of the group context \\
\hline Bigger pool of solution alternatives (Lippmann, 2006) & $\begin{array}{l}\text { Supposition: similar problems or questions (Lippmann, } \\
\text { 2006) }\end{array}$ \\
\hline Multiple feedbacks (Goodstone \& Diamante,1998) & $\begin{array}{l}\text { No group context in acute crisis (George \& Christiani, } \\
\text { 1990) }\end{array}$ \\
\hline $\begin{array}{l}\text { Supporting of learning by positive reinforcement and } \\
\text { vicarious learning (Bandura, 1977) }\end{array}$ & $\begin{array}{l}\text { Limited motivation to open oneself in group context } \\
\text { (Lippmann, 2006) }\end{array}$ \\
\hline $\begin{array}{l}\text { Higher motivation by the presence of colleagues } \\
\text { (George \& Christiani, 1990) }\end{array}$ & $\begin{array}{l}\text { Limited bringing in of personal issues/psychic stress of } \\
\text { individuals not treatable with same attention }\end{array}$ \\
\hline $\begin{array}{l}\text { Supporting the installation of hope (George \& Dustin, } \\
\text { 1988) }\end{array}$ & $\begin{array}{l}\text { Establishing of group norms (George \& Christiani, } \\
\text { 1990; Goodstone \& Diamante, 1998) }\end{array}$ \\
\hline $\begin{array}{l}\text { Self-reflection orientation tends to become group norm } \\
\text { (Wicklund \& Frey, 1993) }\end{array}$ & $\begin{array}{l}\text { Higher challenges to the coach (George \& Christiani, } \\
\text { 1990) }\end{array}$ \\
\hline \multicolumn{2}{|l|}{ Deepened elaboration (Stebler et al., 1994) } \\
\hline \multicolumn{2}{|l|}{ Increased variety of methods } \\
\hline \multicolumn{2}{|l|}{ Time- and cost-efficiency/economy } \\
\hline Recruiting of coaches from the circle of former coaches & \\
\hline
\end{tabular}




\section{Research Questions}

Table 2 illustrates how the current research was linked to Greif's (2008) structure of research and Kirkpatrick's (2006) four-level-taxonomy, yielding three fields of questions:

A. a first piece was about how much the coachees had felt able to discuss issues and what this had led to

B. a second piece of research was about the connection between the variable kind of participation in the group and the variable empowerment of responsibilities by the company

C. a third part was about the participants' experiences of being in the coaching group

\begin{tabular}{llll}
\hline Greif (2008) & \multicolumn{2}{l}{$\begin{array}{l}\text { Research } \\
\text { Questions }\end{array}$} & $\begin{array}{l}\text { Kirkpatrick } \\
\text { (2006) }\end{array}$ \\
\hline Preconditions & (C) - & $\begin{array}{l}\text { 1. 'Happiness' } \\
\text { Indices }\end{array}$ \\
$\begin{array}{l}\text { Success } \\
\text { factors }\end{array}$ & (C) & (A),(C) & $\begin{array}{l}\text { 2. } \\
\text { Measurement } \\
\text { of Learning } \\
\text { 3. }\end{array}$ \\
$\begin{array}{l}\text { Specific } \\
\text { results }\end{array}$ & (A),(B) & (A) & $\begin{array}{l}\text { Measurement } \\
\text { of results } \\
\text { 4. Return on } \\
\text { investment }\end{array}$ \\
$\begin{array}{l}\text { Generally } \\
\text { applicable } \\
\text { results }\end{array}$ & - & (B) & \\
\hline
\end{tabular}

Table 2: Structure, Taxonomy and Research Questions

These question fields became more specific questions:

A1. What did participants find most useful about being in the coaching groups?

A2. What was the impact on their personal development as managers?

A3. In what ways do they believe the organisation benefitted from them having been in the coaching groups?

B. What, if any, correlations are there between participation in the groups and being given additional responsibilities by the organisation?

C. Which factors are identified by participants as contributing to the effectiveness of the coaching groups?

\section{The coaching programme}

The following describes the key elements of the circumstances that were the subject of the research.

Principles

The in-house coaching program was guided by the following principles:

Systemic orientation - when working with individuals or groups, their systemic interconnectedness within the organisational setting has to be taken into account.

The whole is more than the sum of its parts; the synergy effect has to be expressed (Ennen \& Richter, 2010).
Furthermore, this allows for the effects of the reality construct being undertaken by individuals and groups within organisations. Hence methods of systemic transactional analysis (Schmid 1994, 2003; Mohr 2008) and systemic organisational analysis (Mohr 2006a, 2006b, 2009a, 2010) played a prominent role in the coaching.

A Personality-focused approach based on transactional analysis targets the development of the participants' personalities. This refers to their professional roles and is aimed holistically at their behaviour, thinking, and feeling and shaping of relationships. Role Theory (Schmid 2003; Mohr 2010) as well as the concept of EgoStates (Hagehülsmann \& Hagehülsmann 2001; Mohr $2009 b)$ are model theories on which the holistic design of thinking, feeling and behaviour are based.

Ethics: Regardless of whether it concerns individuals or several persons, every kind of work with a client system is guided by ethical rules. This is especially true for today's "Economics dangling on a string". (Mohr 2012). Personal information and data related to in-house counselling are kept confidential. Confidentiality issues merit special attention, because in-house counselling has to be kept apart from a company's human resources development, which of course is very much interested in obtaining the information for individual and corporate human resources planning.

Resource-saving approach and sustainable development: today's scarcest resource is time. Measures need to be planned in a way that makes it possible to achieve a desired change with an economic input of resources. Alibi measures or activities (Look at us, we have done something!) should not be implemented because they have a damaging influence on sustainable positive developments. That means for example that managers and staff should not be merely placed in events; an adequate 'architecture' of person-toperson conversations, tasks handled on-site, and measures for small and large groups must be scheduled to promote development.

Continuing quality improvement: this includes a requirement to permanently improve the quality of one's measures. Essentially this means constant further education and supervision for everyone working within the unit, including the consultant. Continuous evaluation of the programme contributes to improving its quality and an analysis of effects and evaluation of transfer are consistent processes in consultancy.

Unity of diagnosis and intervention: even the first contact with a client is a source of diagnostic information as well as an intervention; the relationship between consultant and client is shaped as a change-oriented kind of relationship from the beginning. Even if a behaviour is not changed, something changes in a person's assessment or approach. De Shazer (1990) wrote that the point is to have clients instead of visitors or moaners, or even cotherapists as Schmidt (2005) added. Coaching is shaped 
by its effects on communication. A coach does not permit denigrations of others (Mohr 2008) without intervening. The underlying basis has to be not to allow hidden levels of communication that make devaluation possible. The emphasis on this fact is important because many clients arrive with a pre-conceived notion concerning the measures without any previous professional diagnosis, especially for in-house coaching where providers may be perceived as vicarious agents of the company. Hence, at the beginning of an educational measure there has to be an initial diagnosis to determine what kind of measures matches the specific question, and this is decided upon together with the client.

\section{Group Elements}

Participation in the groups and the research was voluntary, the groups were closed, and meetings were held outside core time, usually in the evening between 17.00 and $19.00 \mathrm{hrs}$. Groups were formed with members not being in direct organisational relationships. The groups were assembled by the coach after initial conversations in such a way that coherent groups with members of similar background experience but a good mixture of other aspects (temperament, gender) were formed to make joint learning possible.

Groups were formed with members at similar hierarchical levels, to avoid the possibility that higher-level managers would be concerned to be more advanced in their management abilities. Schmid \& Messmer (2005) suggest the impact on corporate culture of a vertical team but this would have increased the complexity of the groups and changed the focus.

Based on the experience that many peer counselling initiatives are phased out over time, this model was intended to achieve greater sustainability. To make it more interesting for participants, it should have a certain stimulation (Berne 1966) and this was ensured not only through the input of changing issues which gave the whole activity a kind of 'academy flavour', but also through 'tour' interventions (e.g. visits to workplaces) and pooling two groups for one meeting (which went well but which groups chose not to repeat too often).

The well-defined presence of a professional coach as head of group meetings was essential. Previous experiences with network groups without an independent head started enthusiastically, but always petered out over time. There is no doubt that peer supervision groups in social professions or Balint (1957) groups in health professions are viable over long periods of time even without having a definite leader. My experiences with peer groups in managing are not as encouraging, however.

A contract regulated attendance for the ten meetings vacation time included - of the closed coaching groups. Absence was excused for just cause. Every meeting of each coaching group contained these four elements: (1) current role statement with initial feedback; (2) input of up-to-date management issues; (3) discussion of case studies from day-to-day practice; (4) conclusion with short evaluation at the end. These elements with their clear structuring allow for many different ways of modification.

(1) Current role statement: this had four perspectives: a brief review of developments after the last meeting; orientation in the here and now; current concerns of participants in their leadership roles; and issues their staff are dealing with at the moment. Even at this stage it was possible for the coach to give a personalprofessional feedback to an individual's personal development and the image the person presents, characterized by respect. This included a possible reframing of the coachee's frame of reference.

In addition, every participant was given the opportunity to ask for a detailed coaching of a personal concern in the form of a case study or a question. This also served to increase attentiveness and the differentiation between perspectives. Leadership roles and staff roles sometimes focus on different topics, e.g. when dealing with demands placed on personnel or participation in labour disputes. It is then that the leadership role issues become obvious. The 'No. 1 - role' idea of is helpful in this context: Within the framework of organisational roles the leadership role can become the role of the employers' representative. This leads towards focusing on the roles in the company but still makes it possible for participants to report on those elements of their private life important for their lifestyle-integration and work-life-balance.

The initial statement was always accompanied by the question regarding the current state of task fulfilment and target achievement. The reason for this procedure was the fact that it would not make sense to talk about marginal sensitivities or comprehension question among participants if there were more pressing economic problems. Altogether this first part was used to determine the current emotional state of all coachees. The first, brief feedback delivered a frame of reference with intervention characteristics, maybe as appreciation of an accomplishment, empathy or an offer of talking about an issue in detail. An offer to use an issue as case example during the meeting could be included. In addition, behaviour modification reinforcement was used in this context to support any progress made since the last meeting.

(2) Input of up-to-date management issues: usually this meant a short presentation (up to 10 mins) of current discussions in management literature or economic trends relevant for participants with accompanying exercise or discussion (20 min). Thus participants became familiar with fundamental principles of leadership psychology within two years. Sometimes, if a lot of coaching questions were made, this part was shifted to the next meeting, because coaching had the highest priority.

(3) Discussion of case studies from day-to-day practice: These case studies were designed as coaching by the coach with the participation of other group members. In 
exceptional cases, executive managers well-versed in coaching conducted single coaching-units within the group under supervision by the coach. With a time-span of up to 90 minutes this part took the longest in every meeting.

(4) Conclusion: The last part of each meeting gave participants the opportunity to focus on and share with the group the principal insights they had gained. This included another chance for intervention by the coach in case somebody forgot something essential or something needed to be clarified.

Transactional analysis concepts applied to process The sequence described above fits well with Hewitt's (1995, 2003) four-phase model: a contact phase ending with a contract, an agreement on procedure; a content phase which is concluded with a decision concerning the focus, which new engagement can refer to behaviour, thinking, feeling or self-perception; a consolidation phase that is a time to operationalize the decision made, to develop and check implementation possibilities for and in reality and which ends when the new features are integrated; and a conclusion phase with a definition of the results and, if need be, further deductions. Another model applied was the Toblerone (Schmid 2003; Mohr 2008), (see Figure 1) meaning that group members experience an increase in competency regarding leadership and marketing, in theoretical knowledge and practical experience, from each session to the next. In this model, the three corners of the 'Toblerone' shape are the ingredients for a learning process developing a professional personality:

Field competence: the ability and willingness to quickly learn the ropes in a new area of expertise are very important traits. Field competence is applied professional competence. The exchange and sharing of experience among members are especially significant.

Soft-fact theoretical knowledge: executive managers had stated during a previously conducted study (Mohr 2008) that theoretical knowledge regarding leadership, communication etc. (e.g. Zur Bonsen 2009; Heinloth 2011) learned during coaching sessions had made a critical difference for them. Theoretical knowledge is seen as essential in other areas of expertise but companies often expect people to learn leadership 'along the way'. Theoretical knowledge also serves to clarify one's self-perception.

Practical testing (action and evaluation): People often repeatedly find themselves in specific situations without gaining any experience. Experience is gained only by actively evaluating how it went.

Transactional analysis concepts applied to content The content used within the groups included various concepts of classical transactional analysis such as autonomy (Berne, 1961; Stewart \& Joines, 1990), ego states (Berne, 1961; Temple, 2002; Mohr, 2000),

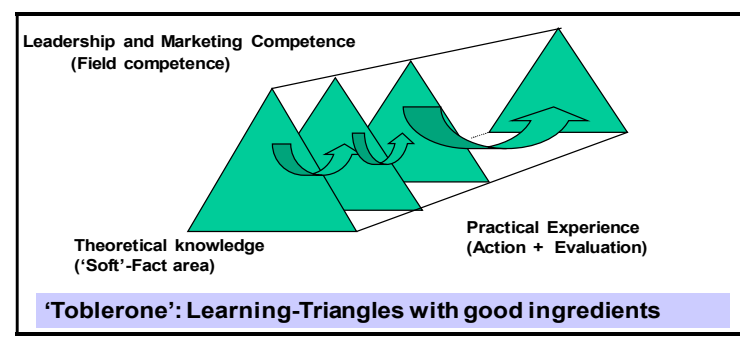

Figure 1: The 'Toblerone-Model' - figure based on Schmid (2003)

transactions (Berne, 1961), symbiosis (Schiff 1975), games (Berne, 1964; Dehner, 2001), and drivers (Kahler, 1977 ) as well as more recent organisational transactional analysis concepts like the role concept (Schmid, 2003; Mohr, 2011), the role symbiosis concept (Schmid, 2003; Mohr, 2006a),) and the system dynamics model (Mohr, 2006a; Mohr, 2011).

The TA models were used by the intervention techniques of Berne (1966). Based on a contract for every piece of work in the coaching, the eight techniques of interrogation, specification, confrontation, explanation, confirmation, illustration, interpretation and crystallisation were used in a coaching appropriate way. This means that they were focused to the here-and-now and participants were not invited to mentally process in an earlier life time (regressive work). The models were applied from a developmental perspective (Hay, 2006). Although some of the models originally were founded by Berne to describe pathological behaviour, in the coaching they are used in a neutral way with both opportunity of describing a problematic side but also to show the specifications and resources of a person. For example, drivers can be seen as negatively causing aspects that limit a person, or as specific working styles that include very relevant resources (Hay, 1993).

Concepts of systemic transactional analysis (Mohr 2008) and systemic organisational analysis (Mohr 2006a),) were utilised, for example, through the model of role worlds (Schmid 1994) which in its current version lists five role worlds (Mohr 2012), as shown in Figure 2. Participants acquire awareness concerning the difference between a person and a role as well as about their own roles in the worlds of company organisation, occupational qualification, private world and community world. That means that coaching need not be limited to mere business skills, but is designed broadly towards the development of a personal professionalism in terms of life coaching (Buer \& Schmidt-Lellek 2008; SchmidtLellek \& Buer 2011). In particular, they learn how to perceive and advance their company organisation and occupational qualification roles professionally. In most cases, an executive manager's self-monitoring with the aspect of incorporating all the role worlds is given priority in coaching. When one perspective is not realised in the long run, problems usually result. 


\section{Dynamics of Roles - Five-Role-World}

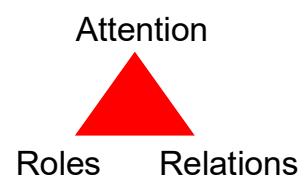

A role is a coherent system of attitudes, feelings, behaviour, perspective on reality and the accompanying relationships (Schmid, 2006, p.34).

Roles Relations

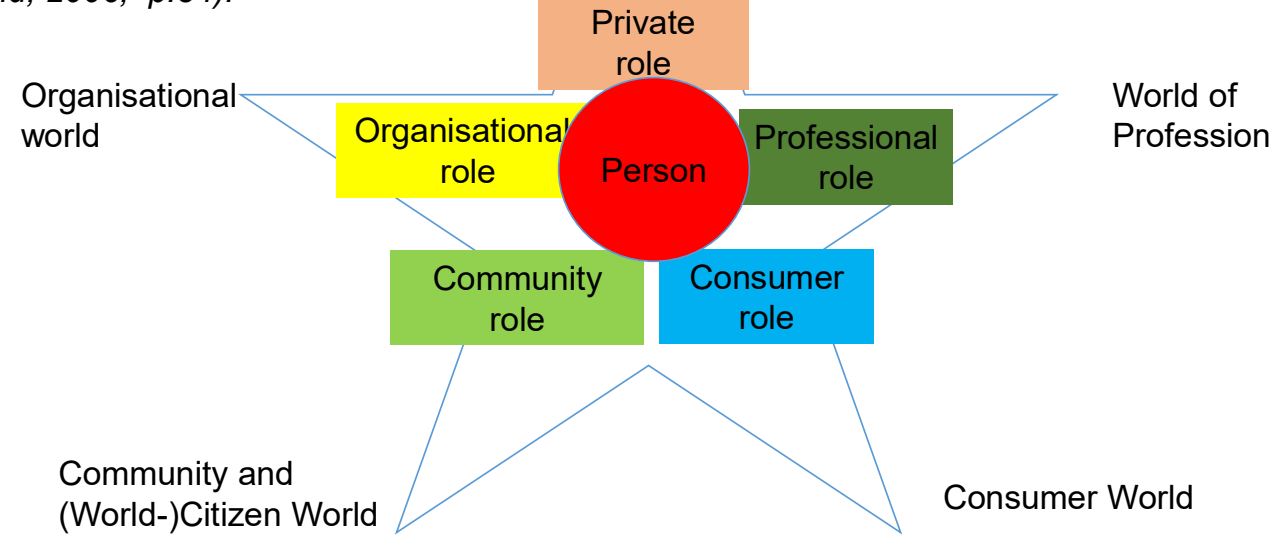

Figure 2: Schmid's (1994) and Mohr's (2012) Model of Role Worlds

\begin{tabular}{|c|c|c|}
\hline Dynamic Fields & Ten System Dynamics & Questions \\
\hline \multirow{3}{*}{$\begin{array}{l}\text { System } \\
\text { Structure }\end{array}$} & 1. Dynamics of Attention & $\begin{array}{l}\text { What are people within the organisation (or unit) currently mainly occupied } \\
\text { with? } \\
\text { What is the relationship between the topic that currently gets the most } \\
\text { attention and the actual goals of the unit? }\end{array}$ \\
\hline & 2. Dynamics of Roles & $\begin{array}{l}\text { Which roles are present within the system? } \\
\text { What are their attributes? } \\
\text { Are these currently changing and, if so, how? }\end{array}$ \\
\hline & 3. Dynamics of Relationships & $\begin{array}{l}\text { How are roles and persons correlated? } \\
\text { What basic messages exist between role protagonists? }\end{array}$ \\
\hline \multirow{3}{*}{$\begin{array}{l}\text { System } \\
\text { Processes }\end{array}$} & 4. Communication Dynamics & What is typical for the way people communicate? \\
\hline & $\begin{array}{l}\text { 5. Dynamics of Problem } \\
\text { Solving }\end{array}$ & $\begin{array}{l}\text { What problems exist at the moment? } \\
\text { How are they dealt with? }\end{array}$ \\
\hline & 6. Dynamics of Success & How is success achieved or avoided? \\
\hline \multirow{2}{*}{$\begin{array}{l}\text { System } \\
\text { Balances }\end{array}$} & 7. Dynamics of Balances & $\begin{array}{l}\text { Who would like to keep which balance? } \\
\text { What balance is aimed for? }\end{array}$ \\
\hline & 8. Dynamics of Recursivity & $\begin{array}{l}\text { How are similar principles put into effect on different levels of the } \\
\text { organisation? }\end{array}$ \\
\hline \multirow[t]{2}{*}{$\begin{array}{l}\text { System } \\
\text { Pulsation }\end{array}$} & $\begin{array}{l}\text { 9. Dynamics of External } \\
\text { System Pulsation (external } \\
\text { boundary, openness, } \\
\text { closeness) }\end{array}$ & $\begin{array}{l}\text { How are the outer boundaries of the system presently evolving? } \\
\text { What measures are necessary to achieve an adequate openness and } \\
\text { closeness? }\end{array}$ \\
\hline & $\begin{array}{l}\text { 10. Dynamics of Internal } \\
\text { System Pulsation (internal } \\
\text { borderlines, subsystems) }\end{array}$ & $\begin{array}{l}\text { What relevant subsystems can presently be distinguished within the } \\
\text { organisation and what are their effects? }\end{array}$ \\
\hline
\end{tabular}

Table 3: Model of Ten System Dynamics (Mohr 2006b) 
Also applied was the model of Ten System Dynamics (Mohr 2006a) shown as Table 3, which helps to analyse every organisational unit as to its current performance and initiate steps for development and improvement. It combines the business-oriented management role and the people-oriented leadership role. Thus, this tool can always be used for stocktaking in everyday coaching. Organizational units of executive managers can consistently be analysed and supported as to their potential.

The model of the ten system dynamics was particularly used to elaborate what is needed in the moment in the teams of the coached managers: which dynamics have certain problems and have to be addressed by management measures?

\section{Ethics}

As formulated in the general contract of the groups it was clear that no personal or department information was brought out of the group room or even given to the personnel department. This was also contracted with the head of the personnel department. The professional ethics of the coach as psychologist also gave the legal base for that.

The participants were informed that the data were to be dealt with anonymously. The handling of the data was managed in a way that no estimation or answer of a single person could be redirected to the person.

\section{Study A: What is important in coaching groups?}

\section{Methodology A}

The first study in January 2007 was to investigate what participants judged important for their learning in the coaching in the year 2006. It was a survey with an evaluation questionnaire that focused on the effects and results that the participants experienced. Results were subjected to content analysis.

Participants A: were 45 managers of the company that had been in the coaching program in 2006. They led teams of 4 to 24 employees, and most had opted for an education in the German "Duales Bildungssystem" (Dual Education System - working in a company accompanied by one professional school day a week). Half of them had also higher education with university degree. There were approximately $50 \%$ men, $50 \%$ women. The age range was 29 to 54 .

The company: was a local service provider for private and corporate customers with stationery distribution. After long-standing tradition it experienced more turbulent times during the previous ten years and was finally taken over by a larger trust under state influence. Due to product disparity the company was not fully assimilated but allowed to function as a discrete unity under the condition of achieving financial objectives. At the time of the survey the company employed 1600 members of staff and about 250 executives on four hierarchical levels.
General market conditions: The company's market was very much affected by the financial and economic crises. Consumers reacted very cautiously to the company's products. The fact that many customers were dependant on basic services provided and were thus a rather faithful clientele had a stabilizing effect, although their migration to internet competitors increased steadily. The earnings generated by providing basic services constituted the financial basis. In addition the company attempted to generate increased transactions through more sophisticated products.

General systemic framework for in-house coaching: There was a long and continuous tradition of innovative education, going back 150 years. The company had always actively supported junior staff development, especially the promotion of its own staff. Only a few external workers, for example with a university degree, were employed. Personnel were socialized into the company through its in-house training system. The company's Coaching unit was instigated and set up in 1999.

\section{Results A}

The highest result was in response to the question about the extent to which participants had been able to discuss in the group the issues and problems that were important to them. $76.5 \%$ gave the highest rating of 'fully satisfactory' and $94.1 \%$ found the group coaching to be instrumental in critical challenges during the year. In addition, other advantages identified included improvement of cooperation, self-management, problem-solving orientation, and manner of cooperation in the group.

References were made to improving cooperation with members of staff (suggestions concerning attitude towards staff, sorting out difficult problems with staff) and continued with personal development as to selfmanagement (demeanour more poised, new points of view in muddled situations, acquirement of new perspectives as to procedure, lessening of self-stress, increased self-esteem, clarification of own rolecompetency, goal-oriented course of action, selfcriticism).

A majority of executive managers emphasized the focus on problem-solving (working out solutions for specific problems, developing different problem-solving strategies allowing for own problems as well as for problems of members of staff, solutions actually being implemented). Overall it became clear that the benefit was not only seen in specific issues being discussed, but also in a culture of development.

Almost everyone emphasized the manner of cooperation. Key words like trusting, open and honest cooperation, discretion, ideal number of participants, homogeneous group, and communicative critical discourse were mentioned. Other important aspects stated were controlling the way the groups worked 
(highest priority for especially pressing problems, inviting participants to state current problems, immediate focus on the root of a problem, agreement with participants) and the autonomous as well as joint development of solutions (finding solutions to problems, autonomous development of solutions, combining own issues with those of others and with theory, support during decisions, suggestions, assistance for further development).

Under personal development of executive managers, there were six dimensions: respecting one's own personality, respecting the personality of members of staff; dealing with crisis situations better; receiving feedback on own behaviour; dealing with change processes within the organisation; and role-awareness as manager within the company and as partner or parent in private life.

For perspective of system qualification, the following effects were described: increased willingness to take up advanced training by members of staff; more direct ways of dealing with conflict; vitalization of communication; better communication and cooperation in collaboration; improved team spirit and development of team spirit in organisation unit on-site; and strenthening of positive attitudes.

\section{Discussion A}

These results definitely speak in favour of using in-house coaching as a means of furthering the education of executive managers. The degree to which they perceived they had got support for their major challenge of the year was particularly encouraging.

\section{Study B: Empowerment and delegation of responsibility by the company in relation to participation in the coaching program \\ Methodology B \\ The research was conducted in 2010 .}

Initially, an analysis using Qualitative Comparative Analysis (QCA) by Ragin (1987, 2000, 2008) was conducted to find out whether participation in a coaching group influenced the professional advancement of the group members. QCA is an algorithmic procedure that was developed as a method between case studies and conventional covariance analyses, able to deliver conclusions as to sufficient and necessary conditions even with limited numbers of cases. It makes it possible to determine configurations of independent variables in socio-scientific contexts e.g. organisational, leading towards a definite specificity of the target variable.

Equifinality is possible, meaning that different configurations of independent variables lead towards a specific result (Fiss 2007). As Katz \& Kahn (1978) emphasise "A system can reach the same final state from different initial conditions and by a variety of different paths" (p. 30, quoted by Fiss 2007, p. 1181). On this basis, QCA as an interesting empirical method is increasingly applied within organisational-theory and economic contexts (Jackson 2005; Bentrop \& Schneider 2012).

QCA was developed by Kagin based on Boolean Algebra with a conceptual foundation in set-theoretical thinking. The algorithm constructed on this basis makes possible conclusions as to acceptable and necessary conditions, and provides information on precisely how much the incidence of specific values of independent variables result in specific magnitudes of the dependent variables, as well as how the absence of specific values of the independent variables leads to the non-occurrence of the dependent variables' magnitudes.

The QCA used in this context was the fsQCA (fuzzy set Qualitative Comparative Analysis) (Wagemann \& Schneider 2007). The situations observed concerning dependent and independent variables were scaled in specific metric increments with a spectrum between 0 and 1.

Independent variables were the length of participation in a coaching group and the meetings' presence quota. The length of participation ran from 'almost no participation', when people only 'got a taste' and then left the group for good to participants with a short duration of participation (up to one year) to participation up to or over three years. Participation was voluntary and absence was allowed in case of good reasons and a timely 'sick note' or a 'very important unforeseeable business date'.

The calibration for the presence quota was measured in a six-level spectrum with the levels being:

$\begin{array}{ll}0 & \text { almost no participation } \\ 0.2 & \text { marginal presence } \\ 0.4 & \text { presence with significant gaps } \\ 0.6 & \text { obvious presence with absence due to external } \\ & \text { reasons (2-3 of } 10 \text { meetings/year) } \\ 0.8 & \text { marginal absence } \\ 1 & \text { almost complete presence }\end{array}$

The resulting variable investigated was 'Transfer of additional responsibility by the company'. The decisions concerning the transfer of responsibility were made exclusively by the company's management and human resource department with no regard to the coaching groups and, because of the coach's professional discretion, also without his expertise. Three levels were chosen for this criterion:

1. The highest level consisted of a conventional promotion towards a higher executive position in a higher hierarchical level, with more staff and higher remuneration (highest value).

2. A somewhat lower categorization was give to a transfer to a leadership position on the same hierarchical level, but with significantly more staff (at least $+50 \%$ ) and usually higher remuneration. 
3. The transfer of an important project task or an additional role (mentor, marketing coach), and an official transfer of responsibility from a hitherto provisional position to a definite, unlimited role, were each given a low, but visible value.

Participants B: The 65 participants were managers aged from 29 to 57, working in locally different departments of the company.

\section{Results B}

As shown in Table 4, the presence quota (the frequent and continuous participation in coaching-groups) was significantly associated with a higher incidence of transfer of responsibility, and in cases of very consistent presence this was highly associated. The consistency value rating the degree of correlation between independent and resulting variable with scores from 0 (no consistency) to 1 (total consistency) added up to 0.82 for both independent variables. The correlation is rather obvious, even assuming a high scale of about 0.75 (Wagemann \& Schneider, 2007) for a meaningful value. The 'coverage'-value, the amount of cases accounted for, is rather high, too, with a value of 0.85 . Another result showed that participants with no significant presence quota could not expect any transfer of responsibility at all.

The length of participation had a somewhat lower significance. With a degree of about $70 \%$ it could be assumed that at least once, but possibly repeatedly, additional responsibility was transferred on permanent coaching-group participants. A necessary condition emerged: without consistency of presence and length of participation even members of coaching-groups were not promoted. The length of participation played a significant role, too, but as soon as it exceeded one year, it was not that important any more.

\begin{tabular}{lll}
\hline QCA-Criteria & & $\begin{array}{l}\text { Relevance points } \\
\text { (Wagemann \& } \\
\text { Schneider, 2007) }\end{array}$ \\
\hline Consistency & 0.82 & 0.75 \\
Coverage & 0.85 & 0.70 \\
\hline
\end{tabular}

Table 4: QCA Criteria

Other independent variables like gender (male, female) or whether someone worked in the factory or in marketing were checked but had no significant influence on the transfer of responsibility; even combinations like 'female marketing staff with high attendance quota and participation between one and three years' did not result in a higher likelihood of responsibility transfer.

\section{Discussion B}

The individual attendance decision, being somewhat constrained because of the groups being closed and because of the necessity of 'sick notes', becomes an interesting quantity in hindsight because of the different ways of handling it. It is closely connected to a third person's totally independent decision, namely, the transfer of responsibility. That means that people who repeatedly concern themselves with the issue of development in the coaching process and who are there for others, too, are obviously spotted for a higher degree of responsibility oftener than those people who do not. The connection between the attendance and engagement in the coaching and the outcome of being given more responsibility might not be the fundamental causal connection. Maybe people who show engagement in the coaching program also do that elsewhere. But it is still interesting that participation in a coaching program also seems to show a very strong correlation between the coaching engagement and the outcome of empowerment.

\section{Study C: Research about effective conditions in coaching-groups}

\section{Methodology C}

Towards the end of 2010 we conducted another research into the effective conditions of the in-house coaching system that had been installed - What is effective in the coaching-groups? This is definitely connected to another question: What makes managers invest their time after their work schedule in coaching?

All 65 executive managers within the system of coaching groups at the time of the survey were given a questionnaire with open-ended questions on the aspects they found important in coaching. The return ratio was very good. Within the three week period the survey was conducted, the differentiated answers of 38 participants, equalling $60 \%$ of the total number of participants were on hand. Altogether the survey resulted in 106 differentiated answers with 403 single items describing the participants' experiences of the effects of coaching groups. A content analysis (Berelson 1952; Mayring 2010) using frequency analysis and valence analysis was done. A frequency analysis studies how often certain terms are being used; a valence analysis evaluates the validation of the terms.

Participants $B$ (same as in Study A): The 65 participants were managers aged from 29 to 57 , working in locally different departments of the company.

\section{Results C}

Table 5 shows the six fields of content analysed and the proportions of mentions. The answers given were very much individually diverse; they show that the individual orientation and thus individual outcomes are of central significance for coaching. There are only a few issues mentioned frequently and even those not very often. The manner of cooperation, a variable of relationship and system, was mentioned in $24.5 \%$ of the answers.

Adding all terms describing cooperation, collaboration, mutual support, team, networking and group makes it evident that this area has the greatest significance. The second most frequent item mentioned were aspects of leadership with a total of $19.8 \%$, a not really surprising result considering the fact that the survey dealt with 
group coaching for executive managers, but which nevertheless was significant in terms of the focus of such measures.

\begin{tabular}{lc}
\hline $\begin{array}{l}\text { Characteristics of Effective } \\
\text { Conditions }\end{array}$ & $\%$ \\
\hline $\begin{array}{l}\text { (1) Basic concept of the coaching } \\
\text { group }\end{array}$ & 30.22 \\
(2) Specific issues dealt with & 11.32 \\
(3) General set-up & 5.67 \\
(4) Role-specific outputs & 16.98 \\
(5) Output quality & 15.09 \\
(6) Effects on corporate culture and & 20.75 \\
system & \\
\hline Table 5: Content Themes
\end{tabular}

Table 5: Content Themes

(1) Basic concept of the coaching group: The basic concept and manner of working in a coaching group were picked out as central theme by $30.22 \%$ of the participants in their statements. Special emphasis was put on a professional fundamental policy making practiceoriented learning possible. That includes the theoretical basis of the procedure which was continually referred to by the coach. All methods applied were substantiated and explained. The professional approach was further characterized by the facilitator offering specific individual coaching as well as by 'neutral' feedback - as seen from the participants' perspective - and support regarding several issues. Comment by one participant included: "Since rather confidential matters are sometimes being discussed it is essential to have an appropriate degree of trust in all the members of a group". Reliability, trust, discretion and candour are the attributes characteristic for the coaching group, according to participants.

Many answers referred to the process of working in groups. The coach's neutrality and autonomy is seen as an important factor. Process elements of the coaching procedure play a prominent role as well. Continually having pointed out several different options for action is one example. Concerning the depth of the approach to solving the problem, there is an appropriate amount of adaptation to necessity, e.g. stimulation, if needed, meaning there was no 'standard procedure', no standard sequence initiated in response to certain questions; intervention was shaped by the needs, and not always 'let's talk about it' or 'let's do a role simulation'. Resource-conserving, especially time conserving procedures were noticed ("fast, efficient, immediately transferable"). The learning process was based on a practical, concrete foundation. The issues and the process had a sound theoretical basis.

(2) Content and issues: With regards to content, the issues were mentioned in $11.32 \%$ of all answers. 'Leadership' is the term mentioned most. Exploration of the meaning of this term and questions of motivation seem to be important. For many group members with multiple roles, especially marketing roles, leadership is a necessary evil, but it can evolve to a fun job through having a forum dedicated to problem-solving. A quotation: "There are continuous leadership instructions given, based on trust and discretion, accompanying the development of the executive manager". Other recurring issues are the pressures as to goals and time especially for marketing staff, a problem aggravated because of the financial crisis which made all transactions with customers more difficult. Especially individual, essential "my organisational unit's concerns" and "my own pressing wishes" are experienced as crucial. There is a certain amount of individuality associated with coaching and group coaching. That includes solutions for personal leadership tasks as well as change processes within the company. Current issues serve to keep up-to-date. The fact that financial pressure, goal-oriented pressure and business strategies that also appeared in other units are being dealt with in a demand-oriented manner is also mentioned in the answers. The chance to be able to "let off some steam", "to get something off one's chest" and to "recharge one's batteries" is seen as equally important.

(3) General set-up: An environment with beneficial conditions, an aspect generally seen as important by human resource managers - and thus often the topic of 'satisfaction questionnaires' - seems to be of less importance to the members of a coaching group and was only mentioned in $5.56 \%$ of all statements. Even then the statements referred to the composition of the group which was controlled - as well as to the fact that participation was voluntary or on the cost/efficiency ratio, especially in terms of time and results. External set-up conditions like accommodation or catering were not mentioned. Even frequent problems with finding a parking space near the educational centre was never cause for complaint. Although the meetings were held within the company, in an educational centre lying only a little bit off the premises, it was experienced as "something outside normal routine".

(4) Role-specific outputs and results: $16.98 \%$ of the answers referred to specific roles, especially to leadership and marketing roles. Notably, concerning leadership issues there is a lot of input in the groups, but also "practical stuff" referring to marketing, which was mentioned repeatedly. In the answers, the complete leadership process is represented, starting with accepting and shaping the leadership role. The interrelationship of professional role and leadership role as well as one's own role within the company were mentioned.

Other role-oriented results were modern, developmentoriented leadership, the initiation and implementation of a leadership conception or becoming acquainted with leadership techniques matched to individual needs. Human resources development and economic thinking and acting support this. Role competency included stress management, problem solving and a better evaluation of 
one's own personality. Leadership theories have to be implemented, special conversational situations for difficult discussions with employees have to be structured and maybe simulated as well. Ideas concerning personnel management or dealing with difficult employees or customers as well as a better orientation of own organisational unit are role-specific outputs.

(5) Output quality and feasibility: Altogether $15.09 \%$ of the answers refer judgmentally to output quality (valence analysis). Common outputs are mentioned in $11.32 \%$ of the answers. Very simply, keywords like "help", "hints" or "proposals" are mentioned. The emotional "outlet effects" (letting off steam) or clarifications, already stated above, also have to be mentioned again here. In detail, specific preparations for situations, an increased level of knowledge and theoretical "equipment" are listed. Participants seem to see the focus in structure and new concepts, less on conserving and stabilizing traditional methods or a historical review of the 'good old days'. The focus is decidedly on developing the new.

Topicality is seen as another important issue. It is put into effect through the current requests experienced and put forth by group members, but also through topical management subjects introduced by the coach. $3.77 \%$ emphasize other aspects of output quality. Feasible results are achieved very fast. It was said that approaches to solving a problem are new. Individuality is highlighted; there are no standard, but only individual, "custom-tailored" solutions. Easily transferable and individual problem-solving solutions for leadership issues are highlighted. Quote: "Comparing notes regularly has a positive influence on resilience, frustration tolerance and therefore on the health status of executive managers."

(6) System and corporate-culture variables: For participants, this category seems to be one focal point as to effects. $20.75 \%$ of the answers dealt with effects on corporate culture and system. Some typical quotes: "Networks within the company come into existence and help solving issues occurring during routine work faster and thus more efficiently, which benefits everybody involved." "There is an increasing amount of understanding when it comes to the wishes and problems of other subunits." "A better understanding is established, a sense of solidarity within the company, that transcends the specific organisational unit. "One effect mentioned even reaches into the private world, it is "weight off the private partner's shoulders." "Individual problems can be looked at from different perspectives, new manners of dealing with it can be developed." The communication in connection with change processes (implementation of new team and group structures) is being accompanied and developed through group coaching. "The better every single executive manager's training, the higher the staffs' quality."

\section{Discussion $\mathrm{C}$}

(1) As to singularity of these results: These results with the coaching groups are similar to experiences made with short-term counselling. De Shazer (1990) reported on his research on the work of Milton Erickson, one of the most important practicing psychotherapists of the 20th century. De Shazer and his Milwaukee-based research group were able to find seven strategic clusters in his procedural method. Doing this, they discovered a problem with the seventh category. This residual category contained a lot of incomparable methods and included $45 \%$ of all case studies. Doubling the numbers of categories to 14 did not help, because it resulted in the $14^{\text {th }}$ category, the new residual category, still containing $35 \%$ of all cases. This shows that the setting of individual patterns is significant. This individual orientation is an integral part of in-house group coaching.

(2) Explicit emphasis on group and teamwork: This corresponds with results from other fields, such as the training of consultants, showing that group-cohesion was an immensely important factor determining the success of the education (Rauen 2007). Coaching groups work rather intensely because of temporal limits, but nevertheless this seems to make sense when working with managers who incorporate the training into their daily routine. Compared to events lasting one or several days and entailing a certain amount of deliberate slowing down with specific rituals for arrival and starting playing a major role, this makes a more resource-oriented, efficient approach necessary. Participants seem to experience this as very appropriate and would have reacted with astonishment to more classical seminar rituals.

(3) Trust and discretion within in-house coaching groups: It is rather interesting to note that in all this time - 10 years - not one case of indiscretion as to personal information has come to attention, although about 120 participants passed through the groups. There is only one case that was reported, of a new female group member who complained to her boss that her coach did not always show the company's merits. During the next meeting she was corrected by another group member who explained the meaning and the approach of coaching to her. This particular case was not without the possibility of leading to significant complications, taking into account the sensitivity of in-house personnel development, because trust can be lost by a single event. In addition, the system of coaching groups was dependent on the support of higher-level executive managers. The important means of existence for the coaching group system was endangered by this event, but it turned out all right because of the immediate correction by another member. In that way, the coaching groups illustrated the positive effects on company culture, because an in-house coaching system can only become part of an organisation if it proves to be immune to external lack of understanding.

(4) Active support, problem actualization, review, mobilization of resources: This is what coaching is about. These issues emphasized by Grawe (1994) can implicitly be deduced from the answers of the participants and are 
surely included, even though they are not distinctly mentioned in open interviews. Participants see effective conditions within a different frame of reference. Especially the aspects of relationships of this form of cooperation, a rather difficult issue in an in-house setting, as well as the pedagogic aspect of management and leadership issues have to be added.

\section{Conclusions: Consequences for in- house group coaching with systemic transactional analysis}

As an overall result several points of reference emerge. Group coaching in the leadership and management area is a very complex, compact personnel development tool. It needs:

1. A learning culture characterised by a protective setting (rules for composition of group, discretion, secrecy as to personal information, openness, trust);

2. General expertise in all aspects of working and professional life (blanket competency);

3. Expertise as to field-specific questions of management (specialist field management knowledge from the branch to the directorate);

4. Psychological expertise (highly qualified coaching role);

5. Up-to-date leadership and management knowledge (academic training, constantly being up-todate in terms of scientific discussions);

6. Expertise as to pedagogy, group dynamics and method competence (training and input-units adjusted to groups working on different levels and with time limits).

Coherence seems to be of the essence. If only one of the six elements is missing, there will be no success, since all of them have to be served because of the individuality of effective conditions. It seems that these are necessary conditions that all have to be guaranteed. Only then will specific problem situations be resolved, resulting in an activity with long-term attraction.

In addition, another central point of reference is the connection to practical leading and managing. Everyday leadership practice offers many causes and opportunities to reflect on and improve leadership. Hands-on learning processes thrive on specific conditions. Of central importance is a protective setting. Coaching group members do not primarily learn a technique, but how to best deploy themselves and their own personality in leadership relations within the company. Just learning techniques does not help at all; to learn about leadership means self-development, and this needs a safe, discreet setting. That can only be provided by an authorized leader or coach who runs no risk of coming into conflict with other roles, and who can legally guarantee the necessary discretion even towards the company, which other role-bearers in leadership or personnel capacities entrusted with disciplinary decisions emphatically cannot.

A second essential aspect is professional diversity as to activities in the coaching groups. With the square shaped by field competence, method competence, theory competence and personal competence (Erpenbeck \& Rosenstiel 2007; Mohr 2008) as goal of their professionalization, executive managers' experience integrated learning due to a well-structured, intervallic procedure. This means that the group leader needs an extensive command of the perspectives of professionalization mentioned above. Accordingly, the requirements are quite exacting. They include coaching and supervision competence, pedagogic competence, being up-to-date as to modern leadership theory and research as well as field competence concerning the working environment of the group members.

The coaching competence of the leader is the third aspect, in order to be able to accompany others in their professional environment and support their development. This especially includes providing the freedom and the chance to enlarge their own spectrum within the confines of the group coaching's time limit.

The leader's knowledge as to the company's own, specific culture should not be disregarded, either. This includes the company's transactions in as many dimensions as possible as well as the specific company itself. This knowledge makes suitable solutions within a limited time frame possible. By undergoing supervision themself the leader maintains their own internal distance and keeps from becoming professionally blinkered.

Günther Mohr is a Teaching \& Supervising Transactional Analyst (Organisational) and can be contacted at info@mohr-coaching.de

\section{References}

Balint, M. (1957) The Doctor, his Patient and the IIlness, London: Pitman

Bandura, Albert (1977). Self-efficacy: Toward a unifying theory of behavioral change.Psychological Review, 84, 191-215.

Bentrop, C., \& Schneider, M. (2012) Neo-Tayloristic or Holistic Work Group: Flexible Production and the Not So High

Performance Work Practices in German Maschinenbau. Study presented at QCA-Konferenz der Universität Hamburg, 1 June 2012.

Berelson, B. (1952) Content Analysis in Communication Research. Glencoe III: Free Press.

Berne, E. (1961) Transactional Analysis in Psychotherapy, New York: Ballantine Books.

Berne, E. (1964) Games People Play, New York: Ballantyne Books

Berne, E. (1966) Principles of Group Treatment, Menlo Park, C: Shea Books. 
Buer, F., \& Schmidt-Lellek, C. (2008) Life-Coaching. Über Sinn, Glück und Verantwortung in der Arbeit. Göttingen: Vandenhoeck \& Ruprecht.

Carter, A. (2013) Coaching programmes in work settings, in Wegener, R, Fritze, A \& Loebbert, M, Coaching-practice fields - research and practice in dialogue (Praxisfelder - Forschung und Praxis im Dialog), Heidelberg: Springer, 415-426.

Cushion, C. \& Lyle, J. (2013): Conceptualising Sport-Coaching - Progressing the Field, in: Wegener/Fritze/Loebbert, Coaching-practice fields - research and practice in dialogue (Praxisfelder - Forschung und Praxis im Dialog), Heidelberg: Springer, 100-110.

Dehner, U. (2001) The daily games in offices. (Die alltäglichen Spielchen im Büro), Frankfurt a.M: Campus.

De Shazer, S. (1990) Der Dreh. Überraschende Wendungen und Lösungen in der Kurzzeittherapie. Heidelberg: Carl Auer.

Deutscher Bundesverband Coaching (Ed.) (2012) Coaching as Profession (Coaching als Profession - Leitlinien und Empfehlungen für die Entwicklung von Coaching als Profession, Kompendium mit den Professionsstandards des $D B V C$ (4., erw. Aufl.). Osnabrück: DBVC Geschäftsstelle.

Ebner, K. (2013) Standardized Coaching for young scientists and students (Standardisiertes Coaching für Nachwuchswissenschaftler und Studierende), in Wegener/Fritze/Loebbert, Coaching-practice fields - research and practice in dialogue (Praxisfelder - Forschung und Praxis im Dialog), Heidelberg: Springer, 101-210.

Ely, K., Boyce, L.A., Nelson, H.K., Zaccaro, S.J., HernezBroome, G. \& Whyman, W. (2010) Evaluating Leadership Coaching: A Review and Integrated Framework. http://www.dtic.mil/dtic/tr/fulltext/u2/a524494.pdf accessed 24 June 2014

Ennen, E., \& Richter, A. (2010) The Whole is More Than the Sum of Its Parts - Or Is It? A Review of the Empirical Literature on Complementaries in Organizations. Journal of Management, 36 (1), 207-233.

Erpenbeck, J., \& von Rosenstiel., L. (Eds.) (2007) Handbuch Kompetenzmessung. Stuttgart: Schäffer Poeschel.

Fiss, P. (2007) A set-theoretical approach to organizational configurations. Academy of Management Review, 32 (4), 1180-1198.

George, Rickey L., \& Christiani, Therese Stridde (1990). Counseling. Theory and Practice (3. Auflage). Englewood Cliffs, NJ: Prentice-Hall.

George, Rickey L., \& Dustin, Dick (1988). Group Counseling: Theory And Practice.Englewood Cliffs, NJ: Prentice-Hall.

Goodstone, Michael S., \& Diamante, Thomas (1998). Organizational Use of Therapeutic Change. Strengthening Multisource Feedback Systems Through Interdisciplinary Coaching. Consulting Psychology Journal: Practice and Research, 50(3), 153-163.
Grawe, K. (1994) Psychotherapie ohne Grenzen. Verhaltenstherapie und psychosoziale Praxis, Jg., Heft 357370 .

Greif, S. (2008) Coaching und ergebnisorientierte Selbstreflektion. Göttingen: Hogrefe.

Hagehülsmann, U., \& Hagehülsmann, H. (2001) Der Mensch im Spannungsfeld seiner Organisation. Paderborn: Junfermann.

Hay, J. (1993): Working it Out at work. Watford: Sherwood Publishing.

Hay, J. (2006): Developmental Transactional Analysis, in Mohr, G. \& Steinert, T. Growth and Change for Organizations, Bonn: Kulturpolitische Gesellschaft, 62-78.

Heinloth, S. (2011) Praxishandbuch für Führungskräfte. München: Hanser.

Hewitt, G. (1995) Cycles of psychotherapy, Transactional Analysis Journal, 25: 3, 200-207.

Hewitt, G. (2003) Cycles of supervision, Presentation at the ITAA-Conference, Oaxaca, Mexico.

Jackson, G. (2005) Employee Representation in the Board Compared: A Fuzzy Sets Analysis of Corporate Governance, Unionism, and Political Institutions. Industrielle Beziehungen, 12 (3), 1-28.

Kahler, T. (1977) The Miniscript (Das Miniskript). In Barnes, G, Transactional Analysis after Eric Berne u.a.

Transaktionsanalyse seit Eric Berne, Bd 2; Berlin, 91-132.

Katz, D. \& Kahn, R.L. (1978) The social psychology of organizations, (2nd ed.), New York: Wiley.

Kirkpatrick, D.L. (2006) Evaluating Training Programs: The Four Levels (3. Aufl.). San Francisco: Berret-Koehler.

Künzli, H. (2009) Wirksamkeitsforschung im FührungskräfteCoaching, in Organisationsberatung, Supervision, Coaching 16, 4-19.

LeUnes, A. (2007) Modelling the complexity of the coaching process: A commentary.International Journal of Sport Science and Coaching, 2(4), 403-406.

Lippmann, Eric (2006). Coaching. Angewandte Psychologie für die Beratungspraxis.Berlin: Springer.

Mayring, P. (2010) Qualitative Inhaltsanalyse. (11 akt. u. überarb. Aufl.). Weinheim: Beltz.

Mohr, G. (2000) Lebendige Unternehmen führen. Frankfurt: FAZ-Buchverlag.

Mohr, G. (2006a) Dynamic Organizational Analysis, in Mohr, G. \& Steinert, T. (Eds): Growth and Change for Organizations, Bonn: Kulturpolitische Gesellschaft, 79-101.

Mohr, G. (2006b). Systemische Organisationsanalyse, Grundlagen und Dynamiken der Organisationsentwicklung. Bergisch Gladbach: EHP. 
Mohr, G. (2008). Coaching und Selbstcoaching mit Transaktionsanalyse. Professionelle Beratung zu beruflicher und persönlicher Entwicklung. Bergisch Gladbach: EHP.

Mohr, G. (2009a) Wirtschaftskrise und neue Orientierung. Berlin: ProBusiness

Mohr, G. (2009b) Ego states: The Unity and the Differentiation Theory (Ichzustände: Die Einheits- und die Unterschiedstheorie), in Zeitschrift für Transaktionsanalyse, 3 , 26. Jahrg 199-218.

Mohr, G. (2010) Workbook Coaching und Organisationsentwicklung. Bergisch Gladbach: EHP.

Mohr, G. (2011) Individual and organizational TA for the 21st Century, Berlin: Pro Business.

Mohr, G. (2012) Ethik in einer Wirtschaft am seidenen Faden, in Zeitschrift für Transaktionsanalyse, 29 (2), 77-99.

Möller, H. \& Kotte, S. (2012). Aktueller Forschungsstand und Implikationen für die Zukunft der Coachingforschung. in Deutscher Bundesverband Coaching e.V. (Eds.). Leitlinien und Empfehlungen für die Entwicklung von Coaching als Profession: Kompendium mit den Professionsstandards des DBVC (4. erw. Aufl.) Osnabrück: DBVC 129-138

Ragin, C. (1987) The comparative method: Moving beyond qualitative and quantitative strategies. Berkeley: University of California Press.

Ragin, C. (2000) Fuzzy set social science. Chicago: University of Chicago Press.

Ragin, C. (2008) Redesigning social inquiry: Fuzzy sets and beyond. Chicago: University of Chicago Press.

Rauen, C. (2007) http://www.rauen.de/coachingartikel/coaching-index-qualitaetsmodell.htm. accessed 24 June 2014

Schiff, J. (1975) Cathexis Reader, New York: Harper \& Row.

Schmid, B. (1994) Wo ist der Wind, wenn er nicht weht, Paderborn: Junfermann.
Schmid, B. (2003) Systemische Professionalität und Transaktionsanalyse. Bergisch Gladbach: EHP.

Schmid, B (2006) Transactional Analysis and Social Roles in Möhr, G \& Steinert, T (eds) Growth and Change for Organisations: Transactional Analysis New Developments 1995-2006, Bonn: Kulturpolitische Gesellschaft 32-61

Schmid, B., \& Messmer, A. (2005) Systemische Personal-, Organisations- und Kulturentwicklung. Bergisch Gladbach: EHP.

Schmidt, G. (2005) Einführung in die hypnosystemische Therapie und Beratung. Heidelberg: Carl Auer.

Schmidt-Lellek, C., \& Buer, F. (Eds.) (2011) Life-Coaching in der Praxis. Wie Coaches umfassend beraten. Göttingen: Vandenhoek \& Ruprecht.

Stebler, Rita, Reusser, Kurt, \& Pauli, Christine (1994). Interaktive Lehr-Lern-Umgebungen. Didaktische Arrangements im Dienste des gründlichen Verstehens.in Kurt Reusser \& Marianne Reusser-Weyeneth (Hrsg.), Verstehen. Psychologischer Prozess und didaktische Aufgabe (S. 227261). Bern: Huber.

Stewart, I. \& Joines, V. (1990) Die Transaktionsanalyse, Freiburg: Herder.

Temple, S. (2002) Functional Fluency Zeitschrift für Transaktionsanalyse 4, 251-269.

Wagemann, C., \& Schneider, C. (2007) Qualitative Comparative Analysis (QCA) und Fuzzy Sets: Ein Lehrbuch für Anwender und jene, die es werden wollen. Opladen: Budrich.

Wicklund, Robert A., \& Frey, Dieter (1993). Die Theorie der Selbstaufmerksamkeit. in Dieter Frey \& Martin Irle (Hrsg.), Theorien der Sozialpsychologie. Band I: Kognitive Theorien (S. 155-173). Bern: Huber.

Zur Bonsen, M. (2009). Leading with life: Lebendigkeit im Unternehmen freisetzen und nutzen Weisbaden: Gabler 